\title{
PRIMARY SCHOOL STUDENTS' PERSPECTIVE OF STRAY ANIMAL ISSUES AND THEIR INTEGRATION INTO EDUCATION
}

\author{
Georgia loannidou $^{1 \star}$, Vasileios Papavasileiou², Dimitrios Poimenidis ${ }^{3}$ \\ ${ }^{1}$ PhD Candidate, University of the Aegean, Greece, gina.ioannidou@gmail.com \\ ${ }^{2}$ Assoc. Prof. Dr., University of the Aegean, Greece, vpapavasileiou@rhodes.aegean.gr \\ ${ }^{3} \mathrm{Dr}$, University of the Aegean, Greece, poimenidis@aegean.gr \\ ${ }^{*}$ Corresponding Author
}

\begin{abstract}
The current paper attempts to investigate the views of primary school students of the $4^{\text {th }}, 5^{\text {th }}$ and $6^{\text {th }}$ grade on the issue of stray animals and its inclusion in the school curriculum. Taking into consideration the negative impact of the existence of stray animals, it is regarded vital to educate children and formulate a policy aiming at minimizing the phenomenon. The lack of knowledge and training concerning the needs and welfare of animals prior to acquiring pets intensifies the issue as the needs of the animals are not fully understood increasing the likelihood of them being abandoned in most cases. Especially during the economic crisis, the incidents of abuse and abandonment increased rapidly. The research was conducted using questionnaires and the results showed incomplete knowledge of addressing the issue and the underlying cause. The students are aware of the animal needs but there are difficulties in proposing effective ways of managing the case. They consider that dogs are more directly dependent on humans than cats. They seem quite positive in their knowledge about dog and cat care. Nevertheless, the students do not prefer to be informed by teachers, as they consider that the teachers are not properly trained, although many of them desire animal care to be a topic in school textbooks. The students seem to have more trust on Animal Welfare Organizations as a source of information regarding animal care. In addition, it seems that fifth graders are more interested in learning about stray animal issues whereas this interest is declining in older students. Research also showed that a gender correlation exists as girls are more positive in terms of animal care awareness.
\end{abstract}

Keywords: Stray animals, students, education, educational policy

\section{INTRODUCTION}

The way animals are treated outlines the cultural identity of a region and it has special significance when based on moral dimensions, regardless of the economic parameters. The presence of stray animals is linked to the transmission of diseases and the burden of the local administration in capturing them and maintaining a stray animal service. Thus, the aim is to decrease the number of stray animals while improving their living, considering the ethical values but not harming the public interest (Kruk, 2021).

The modern lifestyle, the rapid urban development and the technological innovations bring psychological pressure to people who often seek emotional support through their pets, without considering possible difficulties. This irresponsible attitude leads to abandoned pets (Mitrofanova et al., 2018). 
In Greece, $14 \%$ of the households have a dog, while $13 \%$ a cat (Fediaf, 2020). Nevertheless, phenomena of abuse are noticed which seem to become more intense in the province, endangering the lives of animals either intentionally or unconsciously. (Baka et al., 2020). It is interesting that the most prevalent criterion for obtaining a dog is its physical characteristics, which overshadow the health criterion, and this is evident in the choice of certain breeds. It is also considered important that some prospective homeowners are not informed thoroughly before purchasing a dog and their sources are not always reliable, based mostly on the internet. More thorough studies in this field are needed for the design of educational programs that will cultivate values and shape attitudes before acquiring a pet (Holland, 2019), while it is necessary to find strategies that will prevent animal purchase because of selective breeding as breed manipulation can be dangerous for animals (Sandøe et al., 2017).In addition, animal abuse is regarded an international problem, but it has not received adequate attention, and there is minimal research to identify the criteria by which signs of animal cruelty or neglect are indicated (McMillan et al., 2015).Although anthropocentric views play an essential role in human societies, they set aside animal rights and their standpoint in the sustainable environment requires redefinition (Gupta \& Gupta, 2019), as a plethora of dogs and cats end up stray and are considered a problem. In particular, the Non-Governmental Organizations (NGOs) of the western world hasten to address the issue, creating shelters to ensure the animals' welfare and avoid euthanasia (Sandøe et al., 2019). Euthanasia is only allowed in Greece under specific conditions such as aggression, incurable diseases, and non-self-preservation due to old age. In all other cases stray animals are collected and housed either temporarily or permanently in corresponding animal rescue groups. This indicates that in Greece the killing of healthy stray animals is not allowed. After sterilization and deworming, they are reintegrated into the environment they came from (Delistamatis, 2019). Nevertheless, even this option does not ensure welfare and does not provide safe conditions for animals, which are at risk of starvation, dangerous weather phenomena, road accidents, diseases and so on. Furthermore, dangerous conditions emerge such as the transmission of zoonotic diseases to humans and other animals, water and soil pollution, wildlife attraction and general problems related to public safety (Seimenis \&Tabbaa, 2014), namely dog bites to children, which can be partially prevented by proper education (Jakeman et al., 2020). Particularly, in countries that have a considerable number of stray animals, as children often come into contact with them, it is regarded necessary to develop and implement educational programs related to animal welfare that address these issues (Isparta et al., 2021).

In particular, the period of economic crisis has intensified the problems with the increase of aggressive behavior towards animals, whether stray or domestic, and is also a major reason of stray animal overpopulation. The death toll in 2016 reveals a tragic increase in violent cat and dog deaths and predictions for a further escalation in incidents are almost certain. A decisive factor is people's ignorance of the obligations they must undertake when they decide to include a pet in their life. Unconscious decisions and superficial reasons lead to inability to respond to animal needs and welfare. In addition, social attitudes about animals are hopelessly confused and play an important role regarding the violation of animal rights. The lack of education on this issue raises the need for setting solid, coherent policies and plans and identify strategies on which to build sustainable educational systems (Vlemmas, 2017), which will encourage positive behavior and cultivate the emotional dimension through the implementation of educational programs (Silva dos Santos et al., 2020).

\section{METHODOLOGY}

The current paper attempts to investigate the views of primary school students on the issue of stray animals and its inclusion in the primary school curriculum. An anonymous questionnaire was used, with open-ended and closed-ended questions. It was implemented in May 2021 in Rhodes and the sample consisted of 107 of primary school students of the $4^{\text {th }}, 5^{\text {th }}$ and $6^{\text {th }}$ grade. The response data were codified and processed with the SPSS 25 statistical program. The results are presented with descriptive analysis and statistically significant correlations $\left(x^{2}, p \leq 0.05\right)$ emerged from the variables. Regarding the students, $32.1 \%$ attend the 4 th grade, $38.7 \%$ the 5 th grade and $29.2 \%$ the 6 th grade, while 47 of students are boys and 59 are girls. About half of them $(51.9 \%)$ do not owe a pet, $44.3 \%$ say they have a pet, while $3.8 \%$ do not give an answer.

\section{STUDY FINDINGS}

When asked which animals are called stray, most of the students' responses were about either of the animals that do not have an owner $(43.4 \%)$ or a home $(41.5 \%) .11 .3 \%$ of the students respond that stray animals are those that stand alone on streets, while very few (3.8\%) do not answer at all. $75.5 \%$ of students have noticed the existence of stray animals in their neighborhoods, $16 \%$ declare that homeless animals do not exist, while $7.5 \%$ do not give an answer. 
Consequently, regarding the multiple-choice question about the needs of dogs and cats, a differentiation is observed for the two species, with dogs being considered as animals with the most requirements. Concerning animal food, $95.3 \%$ state that it is necessary for dogs, while the percentage decreases to $88.7 \%$ for cats. $91.5 \%$ of the students express their love for dogs while $81.1 \%$ for cats. The need for medical care follows, where $86.6 \%$ consider it necessary for dogs and $78.3 \%$ for cats. Regarding housing, $79.2 \%$ declare that it is important to provide a secure place for dog and $71.7 \%$ for cats. Companionship seems to be recognized for dogs by $76.4 \%$, while for cats by $67 \%$. Animal welfare is perceived as a need by about half of the children and in this case, dogs get a higher percentage (54.7\%) than cats $(47.2 \%)$. Few did not answer this question while $1.9 \%$ stated that they do not know the needs of dogs and $5.7 \%$ declared that they are unaware of the cat needs.

Concerning the feeding of stray animals, $70.8 \%$ of the students state that they do feed them, whereas $20.8 \%$ do not cater for homeless animals; few students (8.5\%) do not give an answer. Moreover, it appears that most students are not intimidated by stray animals $(69.8 \%)$, few $(18.9 \%)$ express a fear of them, while $11.3 \%$ do not answer the question. Consequently, the students who stated that they are not scared of them would adopt a homeless animal while $12.3 \%$ would not attempt it; $17.9 \%$ did not respond to the question regarding the willingness to adopt a stray animal.

When asked if they would like to be informed about issues related to stray animals, we establish that $61.3 \%$ answered positively, $17 \%$ negatively, while $21.7 \%$ preferred not to answer. The results of the survey indicate that the students would like to obtain relevant information from animal welfare organizations (55.7\%), followed by a veterinarian (45.3\%), the internet (24.5\%) and lastly a teacher (with $23.6 \%$ ). $81.1 \%$ justify their answer, stating that each source provides more knowledge on the issues of stray animals, $4.7 \%$ cannot justify their choice, while $14.2 \%$ do not give any answer.

When asked if they preferred the school textbooks to include topics about dog and cat care, most students (70.8\%) responded positively, $13.2 \%$ in negatively, while $16 \%$ did not answer at all.

When asked if they have physically abused a dog or a cat, a small percentage answered positively (5.7\%), while most students $(90.6 \%)$ denied such an act. 3.8\% preferred not to answer. Regarding the question whether they are intimidated by stray animals, the same percentage declined to give an answer in contrast to most students $(87.7 \%)$ who perceive a fear of animals, while few $(8.5 \%)$ consider that stray animals do not feel fear.

Regarding which dogs are considered more dangerous to bite, there is almost no differentiation between dominant and stray animals with $34.9 \%$ and $35.4 \%$ respectively. The remainder of the students $(29.2 \%)$ state that they are oblivious to the issue. In addition, when asked if stray animals can survive outdoors, more than half of the students (59.4\%) believe they cannot, $17.9 \%$ concur that they can whereas $22.6 \%$ of the students do not express an opinion.

Most students $(70.8 \%)$ declare that the main cause of animal homelessness is that pets are abandoned by their owners, few $(6.6 \%)$ consider reproduction as the reason for stray animal existence while $20.8 \%$ are unaware of the origin.

Regarding the question about the harm that stray animals may cause, $44.3 \%$ state they are oblivious to the issue while $6.6 \%$ do not give an answer indicating that most students are unaware of the subject. The remainder of the students cite that apparent issues related to stray animals concern barking and aggressive behavior towards people (26.4\%), scavenging trash in search for food $(10.4 \%)$, the presence of feces $(2.8 \%)$ and uncontrolled breeding (1.9\%). Few of them (7.5\%) believe that stray animals do not cause any harm. However, nearly half students (45.3\%) clearly characterize them as harmless, $29.2 \%$ believe that they are dangerous, while about a quarter of them (25.5\%) state that they are unaware of the issue.

Lastly, the students were asked, through an open-ended question, to suggest ways to address the issue of stray animals. Most of them (69.8\%) proposed the adoption, followed by the intervention of animal welfare organizations $(34 \%)$. Few of them (14.2\%) suggested pets should not be abandoned by their owners, followed by vaccination $(1.9 \%)$ and sterilization $(0.9 \%)$ as well as the imposition of fines on those who their pets $(0.9 \%)$.

During data processing, several statistically significant correlations were found, which are presented below. Regarding gender, it appeared that girls $(61.5 \%)$ are more willing to be informed about stray animals $\left(\mathrm{X}^{2}=\right.$ $9.916 \mathrm{df}=2 \mathrm{p} .=0.007)$ compared to boys $(38.5 \%)$.

Regarding which animals are classified as stray, $40.9 \%$ of the sixth graders believe that stray animals are the homeless ones while $29.5 \%$ of the fourth and fifth grade students have the same opinion. Moreover, only 
$10.9 \%$ of the sixth-grade students correlate stray animals with those being homeless based on irresponsible owners as opposed to the fourth and fifth graders where the percentages range between $41.3 \%$ and $47.8 \%$ respectively. None of the fourth graders $(0 \%)$ give any interpretation regarding the animals that stand alone on streets while the percentage is divided equally by the fifth and sixth graders $(50 \%)\left(X^{2}=16.816 \mathrm{df}=4 \mathrm{p} .=\right.$ 0.002).

Moreover, the findings indicate that there is correlation between the desire to adopt a stray animal and age where the highest percentage (41.9\%) appears in the fifth grade, followed by the fourth grade $(37.8 \%)$ and a smaller percentage in the sixth grade $(20.3 \%)\left(X^{2}=11.776 \mathrm{df}=4 \mathrm{p} .=0.019\right)$. The sixth graders $(18.5 \%)$ also show lack of interest about being informed about stray animals whereas the students of the fifth grade constitute the majority $(44.6 \%)$ followed by the fourth graders $(36.9 \%)\left(X^{2}=9.616 \mathrm{df}=4 \mathrm{p} .=0.047\right)$. In addition, the inclusion of animal care in school textbooks seems to be of more interest to the fifth graders $(44 \%)$, followed by the fourth graders $(37.3 \%)$, while the students of the sixth grade seem less interested $(18.7 \%)\left(X^{2}=15.499 \mathrm{df}=4\right.$ p. $\left.=0.004\right)$.

With reference to the question whether stray animals are dangerous or not, the sixth graders declare ignorance of the subject $(51.9 \%)$ followed by the students of the fifth grade $(33.3 \%)$ and lastly the fourth graders $(14.8 \%)$ who state that they are unaware of the issue. Thus, with the conviction that stray animals are harmless, the fourth graders appear with a highest percentage (41.7\%), followed by the fifth graders with $39.6 \%$, whereas only $18.8 \%$ of the sixth-grade students believe that the homeless animals are not dangerous $\left(X^{2}=10.831 \mathrm{df}=4\right.$ p. $\left.=0.029\right)$.

\section{DISCUSSION AND CONCLUSSIONS}

The students' responses indicate that at first the concept of stray animals is intertwined with either the lack of pet ownership or homelessness, with no clear distinctness between the two definitions. According to the international bibliography, the terms pets, stray animals and wild animals do not seem to follow a consistent interpretation. Nevertheless, Farnworth et al. (2011) define pets as animals that depend exclusively on human care, while stray animals as the ones that have been abandoned or lost and are indirectly dependent on individual concern but live in residential areas. Hence, this conveys that in both cases providing food directly or indirectly is considered a primary need for children, as it is directly related to the survival needs of stray dogs and cats, a fact which the students are actively involved according to their statements. Apart from providing animals with food for their survival, love appears first in the hierarchy as a primary need. Children of this age often identify with animals and project their inner world through them, giving anthropomorphic characteristics to animals (Pagani, 2011). Thus, the subsequent reports are related to medical care and housing. A high percentage of the animal need for socialization is also found reinforcing the view that building positive relationships between children and animals contributes to the socialization of the child as well (Prothmann \& Tauber, 2010). Half students consider that it is necessary pets to be kept entertained, although the more intelligent and sociable an animal is, the more adequate stimuli are necessary (Mamzer, 2020). The tendency that animals have when sleeping for several hours seems to be linked to lack of mental stimuli that cause boredom when owners do not interact with them on a regular basis (Pollick, n.d.). However, in relation to the above needs, a differentiation between cats and dogs is seen as domestic dogs are considered more dependent on humans for primary reinforces. This would explain the fact that dogs are regarded more popular than cats (Vonholdt \& Driscoll, 2017) or from the perspective that cats are more independent (Eriksson et al., 2017).

Although students affirm that they are not afraid of stray animals, less than three-quarters of them prefer to adopt one. Concurrently, opposing viewpoints seem to be regarding how dangerous dogs are, based on the distinction between domestic and stray ones. It seems that they do not feel utterly safe with the presence of either category, and this belief is reinforced by the degree of ignorance in the question, although most children recognize that the human presence may cause fear in animals resulting in undesirable behavior (Puurunen et al., 2020). Furthermore, more than half students believe that homeless animals can survive on their own in the streets, although their survival depends on the interaction with humans (Brock, 2018).

In addition, the students indicate lack of knowledge about the damage that stray animals can cause, although their increasing number raises socioeconomic and public health issues (Szwabe \& Blaszkowska, 2017).

Regarding the students' proposals of the ways to deal with the situation, animal adoption is prevalent, while it is noteworthy that the percentage of those who propose it is the same of those who are not afraid of stray animals as well as those who initially expressed the desire to adopt. It is probable that the personal will is reflected in the solutions of the issue and cannot exceed the individual possibilities. Thus, we see the 
problem shifting to animal welfare organizations, while few students perceive humans are the primary cause of abandoning a pet animal (Jensen et al., 2020). Additionally, almost non-existent are the suggestions of sterilization and vaccination for animal welfare, which require a veterinarian.

Lack of knowledge on key points is evident, but the number of children who would like to be informed about stray animals is inadequate. What is more, the students show less trust in the teachers for stray animal orientation, as they apparently do not consider that teachers have the appropriate knowledge about the issue, while they highlight animal welfare organizations as the key source of information. In fact, even the internet, although not considered valid enough (Holland, 2019), is preferred as a source of information in relation to teachers who are last in preferences as a source of information. Though, they agree to a greater extent that the issue of stray animal welfare be included in school textbooks. Moreover, the girls excel in their desire to be informed about the subject. It can be inferred that the students believe that their teachers do not have the appropriate background to approach the issue, possibly because there is no reference in school textbooks. Apparently, further research is needed to substantiate whether the teachers' knowledge is insufficient, and their attitudes do not predispose to the implementation of programs and interventions related to the subject.

Regarding the students' age, the fifth graders appear to be the most positive on the issue of animal adoption and the subject of stray animals in education, although primary school children generally have the mental infrastructure to understand the needs of animals (Lawrence et al., 2010) as they grow older, and their experiences increase resulting in enhancing their cognitive abilities (Allen, 2015). On the other hand, the sixth graders show less interest to be informed about stray animals and increase their knowledge on the issue, leading to the preservation of anthropomorphism and the projection of the same emotions, resulting in the development of a latent empathy that can have a negative impact on both animals and humans (Young et al., 2018). As the case may be, the reduced interest is due to the fact that at the age of 9-12, pet ownership appears more attractive, while this trend begins to decline when entering adolescence (Jacobson \& Chang, 2018). Consequently, educational intervention should start at an early stage.

According to the study findings, it seems that the girls are more interested in being informed about animal care, a fact that the research of Hawkins et al (2017) confirms, which was established that girls of all ages are more attached to pets, and they have a higher score on compassion, care and generally a positive attitude towards animals.

In accordance with the statements, there was no correlation regarding animal ownership and this finding is not confirmed in the research of Prokop \&Tunnicliffe (2008), in which the analysis indicated more knowledge about animals and more positive attitudes in children who owned animals.

It becomes apparent that it is necessary to design appropriate teaching and learning strategies for the formation of active citizens who will prevent the population of stray animals which is rising in urban areas. The experiences of the animal welfare organizations, the veterinarians' knowledge in collaboration with the teachers and the pedagogical process can contribute to the prevention and the optimum solution of the issue.

The problem of stray animals and its effects not only on human beings but also on the animals themselves is serious and has many negative impacts on city environment and human health. The solution lies in people's attitudes, and it depends on them to reduce the stray animal population in an act of animal welfare spirit. Inadequate education, which results in misinformation about the duties to pets, exacerbates and perpetuates the problem. It is imperative that the issue of stray animals be perceived as the people's responsibility to take care of their pets and as humans to be the primary cause of animal abandonment. Consequently, education is called to play a vital role starting from primary schools to shape responsible citizens to prevent the phenomenon from spreading in the first place. Students seem to lack knowledge of the subject which hinders the distinction of the original cause, while it does not help to address the existing issue. Animal care should be included in the School Curriculum in order to prevent future growth of homeless animals to strengthen the cultivation of animal welfare values that enhance the quality of life and promote human culture.

\section{REFERENCE LIST}

Allen, M. (2015). Preschool Children's Taxonomic Knowledge of Animal Species. Journal of Research in 
Proceedings of INTCESS 2022- 9th International Conference on Education \& Education of Social Sciences 17-18 January 2022- Online Conference

Science Teaching, 52(1), 107-134.

Baka, A., Ntorli, V. \& Argyri, P. (2020). Animal rights. Open Schools Journal for Open Science, 3(3).

Brock, C. (2018). Urban animals: gis analysis of stray canines and felines in Albuquerque, New Mexico. Accessed 25.11.2021 from https://digitalrepository.unm.edu/geog etds/42

Delistamatis, B. (2019). Principles of bioethics and euthanasia of pets. Thesis, Faculty of Health Sciences, Department of Medicine, Democritus University of Thrake. [In Greek]

Eriksson, M., Keeling, L.J. \& Rehn, T. (2017). Cats and owners interact more with each other after a longer duration of separation. PLOS ONE, 12(10), e0185599. https://doi.org/10.1371/journal.pone.0185599

Farnworth, M. J., Campbell, J. \& Adams, N. J. (2011). What's in a Name? Perceptions of Stray and Feral Cat Welfare and Control in Aotearoa, New Zealand. Journal of Applied Animal Welfare Science, 14(1), 5974. doi: $10.1080 / 10888705.2011 .527604$

Fediaf. (2020). Facts and Figures. European Overview. https://fediaf.org/images/FEDIAF Facts and Figures 2020.pdf

Gupta, N. \& Gupta, R. K. (2019). Animal Welfare and Human Health: Rising Conflicts over Stray Dogs in Chandigarh. South Asia Research, 39(3), 339-352. https://doi.org/10.1177/0262728019868895

Hawkins, R. D. Williams, J. M. \& Scottish Society for the Prevention of Cruelty To Animals Scottish Spca (2017). Childhood Attachment to Pets: Associations between Pet Attachment, Attitudes to Animals, Compassion, and Humane Behaviour. International journal of environmental research and public health, 14(5), 490.https://doi.org/10.3390/ijerph14050490

Holland, K. E. (2019). Acquiring a Pet Dog: A Review of Factors Affecting the Decision-Making of Prospective Dog Owners. Animals, 9(4), 124. https://doi.org/10.3390/ani9040124

Isparta, S., Kaya, U., Sahin, O., Safak, C.,E., Ozer, I.Y., Heath, S., Papadatou - Pastou, M. \& Salgirli Demirbas, Y. S. (2021). The first assessment of a dog bite prevention program for pre-school children in Turkey. Journal of Veterinary Behavior, 46, 79-86.

Jacobson, K. \& Chang, L. (2018). Associations Between Pet Owner ship and Attitudes Toward Pets With Youth Socioemotional Outcomes. Frontiers in Psychology, 9, 2304. doi: 10.3389/fpsyg.2018.02304

Jakeman, M., Oxley, J. A., Owczarczak-Garstecka, S. C. \& Westgarth, C. (2020). Pet dog bites in children: management and prevention. BMJ Paediatrics Open, 4(1), e000726. https://doi.org/10.1136/bmipo2020-000726

Jensen, J. B. H., Sandøe, P. \& Nielsen, S. S. (2020). Owner-Related Reasons Matter more than Behavioural Problems-A Study of Why Owners Relinquished Dogs and Cats to a Danish Animal Shelter from 1996 to 2017.Animals, 10(6), 1064. doi:10.3390/ani10061064

Kruk, E. (2021). Polish and Estonian Regulations on Homeless (Stray) Animals. Studia luridica Lublinensia, Vol. 30 (1), 145-166. doi: 10.17951/sil.2021.30.1.145-166.

Lawrence, A. B., Muldoon, J., Lakestani, N., Currie, C.E. \& Williams, J. (2010). Welfare Education: Evidence for Action. International Conference on Animal Welfare Education: Everyone is Responsible. European Union, Brussels, 1-2 October 2010.

Mamzer, H. (2020). Lack of environmental enrichments in shelters for homeless animals: animal welfare and human perceptions for animals' need. Medycyna Weterynaryjna, 76(5), 273-281.

McMillan, F. D., Duffy, D. L., Zawistowski, S. L. \& Serpell. J. A. (2015). Behavioral and Psychological Characteristics of Canine Victims of Abuse. Journal of Applied Animal Welfare Science, 18(1), 92-111, http://dx.doi.org/10.1080/10888705.2014.962230

Mitrofanova, Yu. S., Fedorchuk, V. K, Grigoryeva, V. E., Buslaev, I. S., Kurbanov, A. R., Gurbanov, A. R. \& Belyalova, M. A. (2018) Student Environmental Attitude Towards Stray Domestic Animals. Ekoloji 27(106), 1895-1902.

Pagani, C. (2011). Children and Adolescents Who Are Kind to Animals. In C. Blazina, G. Boyraz \& D. ShenMiller (eds.), The Psychology of the Human-Animal Bond. Springer, New York, Dordrecht, Heidelberg, London.

Pollick, M. (n.d.). Do Animals get Bored? Accessed from https://www. allthingsnature.org/do-animals-get- 
bored.htm

Prokop, P. \& Tunnicliffe, S. D. (2008). Effects of Having Pets at Home on Children's Attitudes toward Popular and Unpopular Animals. Anthrozoos, 23(1), 21-34.

Prothmann, A. \& Tauber, E. (2010). Pets in Pediatrics-current Status of Animal-assisted Interventions in Pediatric Hospitals in Germany. 12th International IAHAIO Conference Stockholm. July 1-4, 2010, Stockholm, Sweden.

Puurunen, J., Hakanen, E., Salonen, K. M., Mikkola, S., Sulkama, S., Araujo, C. \& Lohi. H. (2020). Inadequate socialisation, inactivity, and urban living environment are associated with social fearfulness in pet dogs. Scientific Reports, 10, 3527. https://doi.org/10.1038/s41598-020-60546-w

Sandøe, P., Jensen, J., Jensen, F. \& Nielsen, S. S. (2019). Shelters Reflect but Cannot Solve Underlying Problems with Relinquished and Stray Animals-A Retrospective Study of Dogs and Cats Entering and Leaving Shelters in Denmark from 2004 to 2017. Animals, 9(10), 765. https://doi.org/10.3390/ani9100765

Sandøe, P., Kondrup, S. V., Bennett, P. C., Forkman B., Meyer, I., Proschowsky ,H. F., Serpell, J. A. \& Lund, T. B. (2017). Why do people buy dogs with potential welfare problems related to extreme conformation and inherited disease? A representative study of Danish owners of four small dog breeds. PLoS ONE 12(2). e0172091. doi:10.1371/journal.pone.0172091.

Seimenis, A. \&Tabbaa, D. (2014).Stray animal populations and public health in the South Mediterranean and the Middle East regions. Veterinaria Italiana, 50 (2), 131-136. doi: 10.12834/Vetlt.48.134.3.

Silva dos Santos, M., Kelsey, K. D., Fuhrman, N. E. \& Irwin, K. (2020). Animals in Environmental Education: Assessing Individuals' Emotional Reactions to Interactions with Wildlife. Journal of Agricultural Education, 61(4), 61-77. https://doi.org/10.5032/jae.2020.04061

Szwabe, K. \& Błaszkowska, J. (2017). Stray dogs and cats as potential sources of soil contamination with zoonotic parasites. Annals of Agricultural and Environmental Medicine, 24(1), 39-43.

Vlemmas, I. C. (2017) Economic crisis and pet animal abuse. Hellenic Journal of Companion Animal Medicine, 6(1), 5-8. Accessed 20 July 2021 from https://www.hjcam.hcavs.gr/index.php/hjcam/article/view/61

Vonholdt, B. \& Driscoll, C. (2016). Origins of the dog: Genetic insights into dog domestication. In J. Serpell (Ed.), The Domestic Dog: Its Evolution, Behavior and Interactions with People (pp. 22-41). Cambridge: Cambridge University Press. doi:10.1017/9781139161800.003

Young, A., Khalil, K. \& Wharton, J. (2018). Empathy for Animals: A Review of the Existing Literature. Curator: The Museum Journal, 61, 327-343. 